\title{
The Evolving Dynamics of Environmental Policy in Kenya
}

\author{
Hemal Thakker \\ School of Liberal Studies, Pandit Deendayal Petroleum University
}

\begin{abstract}
The consequences of climate change, apart from being serious challenges to humanity, are especially threatening to develop countries. Climate change endangers human health through its effects on the stability of ecosystems and acts as a catalyst to disease pandemics. Multilateral climate change treaties serve as vital mechanisms to foster state-level action against the threat of climate change - super-conventional warfare. International treaties and collective regional and/or global policy could spur domestic action to address the health hazards caused by climate change. However, developing countries face multi-dimensional challenges in implementing environmentally viable policies to address climate change. The efficacy of policies and laws indeveloping countries within the shifting global climate change paradigmgives rise to a number of legal and pragmatic questions. Developing countries, therefore, must move for reforms at the institutional level to promote conservation of environment and resources, and address the pressing questions regarding climate change.

There have been efforts to reach a global consensus to address climate change, which has resulted in the industrialized North inimical to the developing South. The global North seems to emphasize on the shared responsibilities of allnations to reduce emissions while the global South waves the flag of differentiated responsibilities. The global North-South negotiations are derived from inequalityin the historical and current levels of emission of greenhouse gases, the emerging consequences of climate change in the face of the geopolitical landscapebetween modern nation-states.
\end{abstract}

The basic tenets of 'Kenya Vision 2030' and the 'Constitution of Kenya 2010' are steady growth and sustainable development.The Constitution recognizes a clean and healthy environment as a basic human right and provides for sustainable exploitation, utilization, management and conservation of the environment and natural resources. Kenya affirms, cognizant of the challenges faced today, that it is committed to undertaking a transition to a green economy in line with the outcome of the United Nations Conference on Sustainable Development (UNCSD) held in 2012. The outcome document of the Rio+20 summit; The Future We Want, (UNCSD, 2012) highlighted transition to a green economy as a means towards sustainable development. Transitioning could contribute to "eradicating poverty, as well as sustained economic growth, increasing social inclusion, improving human welfare, and creating opportunities for employment and decent work for all, while maintaining the healthy functioning of the Earth's ecosystems."

The Kenyan govt. is developing a green economy strategy to support development efforts towards addressing key challenges such as poverty, unemployment, inequality, environmental degradation, climate change and variability, infrastructure leakages and food insecurity. The Kenya Green Economy Assessment Report launched by the UNEP (2014) concluded that Kenya is already implementing various green economy approaches and policies and that the transition to a green economy reflects positive impacts in the medium and long term across sectors of the economy. By 2030, a green growth path will result in faster growth, a cleaner environment, and high productivity, relative to the 'business as usual' growth scenario. In the Medium Term Plan 2013-2017, the Government committed to developing a Green Economy Strategy.

There is also a need to ensure that work designed to facilitate the transition to a green economy is consistent with the Sustainable Development Goals (SDGs) envisioned at Rio+20. The SDGs cover various aspects of sustainable development from ending poverty and hunger, to health, equality and inclusion, and access to energy. Green Economy provides an avenue for functional interaction between Economy and the SDGs. The SDGs, although pending adoption, provide a framework within which green growth targets can help reorient national economic development planning as well as guide the behavior of both the public and private sectors.

Therefore, we seek to understand, through this paper the evolution and impact of various mechanisms of the Kenyan environmental policy as well as examine Kenya's transition to becoming 'Green economy.

Keywords: Climate Change, Environment, Policy, Sustainable Development, Growth, Green Economy

\section{Introduction}

The positive denouement of Kenya's constitutional referendum in 2010 transformed the unicameral parliament into a bicameral parliament that in the status quo incorporates a National Assembly and a Senate. 
This paper discusses the metamorphosis of the Kenyan Political System in correspondence with its environmental policy. It aims at analyzing the Kenyan Political System by dividing into three republics; the first republic (1963-1978), the second republic (1978-2002) and the third republic (2002- Present). The primary focus of this paper will be to examine Kenya's transition to becoming a 'Green Economy.'

\section{Kenya's Transition into a Green Economy}

\subsection{Political Background (1963- Present)}

Kenya gained independence from the British on $12^{\text {th }}$ December 1963. The Kenyan African Union (KAU) which was regarded as Africa's first genuine nationalist organization and was fundamentally the core of the freedom struggle of Kenya was established in 1944. Ethnicity has perennially been the crux of the Kenyan socioeconomical and political setup.This paved the way for the rise of Jomo Kenyatta, who returned to Kenya from Britain in 1946. His stay in Britain proved crucial as he became involved with some radical anti-colonial organizations and traveled to the Communist-sponsored International Trade Union of Negro Workers in Hamburg. He also traveled to Berlin and spent several weeks in the Soviet Union in August 1929. Jomo Kenyatta is regarded as one of the main pioneers of African nationalism along with the likes of Kwame Nkrumah and George Padmore. Kenyatta became an unrivaled leader as he was widely accepted by politically conscious Kenyans and became the president of the KAU in 1947. His efforts to unite the non-kikuyu tribes to join the movement were successful, and membership in the Kenyan African Union increased by over 100,000. Kenyatta's ambition was to bring these politically discordant bodies into the KAU.

The Mau Mau uprising was one of the focal points of the Kenyan independence struggle. It largely comprised of members from the Kikuyu tribe. The Mau Mau revolt lasted from 1952 through 1960. In 1952, they had initiated a campaign against the highland settlers. This campaign resulted in thousands of casualties due to widespread violence. In retaliation, the KAU was banned in 1953, and Kenyatta was imprisoned. The cornerstone of the Kikuyu grievances which led to the Mau Mau uprising was the land grabs effectuated by the settlers. The Mau Mau resorted to violence to accomplish objectives identical to those of KAU, like land tenure security, representation in Government, better wages and working conditions. Many people from the Kikuyu tribe were repatriated and hence, they fled into the forests to evade repatriation. The Mau Mau uprising primarily recruited these people in the forests.The Mau Mau also comprised of urban workers, peasants, the unemployed, World War II veterans, laborers, and unionists. The Mau Mau trained, launched guerrilla attacks against colonial settlements as well as camouflaged themselves in the forests. In 1957 African members were elected to the Legislative Council through a restricted franchise. ${ }^{[1]}$ However, African members including a Luo trade unionist Tom M'boya who played a vital role in Kenya's freedom struggle refused to assume official responsibilities. A constitutional conference was held in London in January and February 1960 that led to a transitional constitution legalizing political parties and giving Africans a comfortable majority on the Legislative Council. The Kenya African National Union (KANU) was subsequently inaugurated as it presented an unyielding stance on land resettlement in the highlands. M'boya and James Gichuru became the leaders of KANU because Kenyatta remained in detention. Other African politicians who were wary of Kikuyu-Luo supremacy favored a more federalist government and therefore, formed the Kenya African Democratic Union (KADU). When Kenyatta was released in August 1961, he formed an all-party government and accepted the KANU presidency. At the Legislative election in May 1963, KANU prevailed, and Kenyatta was elected prime minister. Kenya was formally declared independent on $12^{\text {th }}$ December 1963.

Kenya was officially declared as a republic in December 1964 with Jomo Kenyatta as its first president. The members of KADU had shifted their allegiances to KANU making Kenya a de facto one-party state. However, certain factions split like Odinga resigned from the vice-presidency to form the Kenya People's Union (KPU) in 1966. Ethnic chauvinism materialized when M'boya, then the KANU secretary-general, was assassinated by a Kikuyu in 1969 under ambiguous circumstances. The Luo population saw his death as an ethnic aspersion and as an attempt to intimidate it politically. Ethnic chauvinism escalated rapidly over the next few months, reaching a point in October 1969 when the KPU was banned, and its principal leaders, including Odinga and seven other party representatives, were detained. The one party state was reinforced as Kenyatta was elected unopposed to a third presidential term in September 1974. 
Kenyatta died in August 1978, at the age of 82, and was replaced by Vice President Daniel Arap Moi, which denotes the beginning of the second republic (1978-2002). In November 1979, Moi won national elections running as the sole candidate. In 1982, there was political turmoil as the Kenyan Air Force attempted a coup d'état that was linked to Odinga, who was placed under house arrest. Political detentions and press censorship were on the rise and as a result in September, with only $48 \%$ of the electorate casting ballots, Moi was re-elected for a second term, unchallenged. Presidential power was further escalated in December 1986 when parliament passed a constitutional amendment that increased the president's power over the civil service and the judiciary that extended to the power to dismiss the Attorney General without recourse. However, factions such as Mwakenya (Swahili for Union of Nationalists to Liberate Kenya)expressed dissent against the Moi regime. By the end of the 1980s, Kenya had become a classic example of "big man" rule identical to Mobutu Sese Seko in the former Zaire and Robert Mugabe in present-day Zimbabwe - Kenya was transformed into a kleptocracy.Opposition to Moi's regime augmented in the 1990s as public pro- democracy rallies held by Raila Odinga, who was the son of the former vice president and other emerging leaders were halted.

Due to the immense pressure on President Moi, in 1991, The National Assembly promptly amended the constitution to allow for multi-party elections. By the beginning of 1992, two clear opposition parties had emerged: Mwai Kibaki's Democratic Party and Odinga's FORD. Several smaller parties were also registered, including the Social Democratic Party, the Kenya National Democratic Alliance, the People's Union of Justice and New Order and Islamic Party of Kenya. ${ }^{[1]}$. Civil unrest and political strife continued over the next few years as ethnic chauvinism escalated and tribal conflicts materialized. Despite all the obstacles and opposition, President Moi retained power in 1993, for another five-year term.

The third republic (2002 - Present) is highlighted by Kenya's transition into a becoming a democracy with Kibaki's party, the National Rainbow Coalition (NARC) defeating KANU in parliamentary elections, winning 132 seats to KANU's 67.On December 27, 2002, more than five million Kenyans went to the polls to elect Mwai Kibaki as their country's third president which marked Kenya's first electoral change of government since independence. The election pronounced the end of the 24-year presidency of Daniel Arap Moi and an opportunity for Kenya to return to its once acclaimed record of political stability and economic growth. On the contrary, the 2007 elections evoked ethnic violence triggered by disputed election results. In the build-up to the elections, two parties were vying for power, the Orange Democratic Movement (ODM) and Party of National Unity (PNU). Due to the discrepancies in the results, there was widespread violence and ethnic conflict. This could be termed as the 'dark phase' in Kenyan political history. The mediation process was successful predominantly due to international actors and the civil society which led to a political settlement resulting in formation of the Unity Government. The roots of this crisis were laid by the Kibaki Government, which engaged in rampant corruption, arbitrary land grabbing by the elite and failure to deal with social evils such as unemployment and landlessness.

In 2010, the landmark referendum for a new constitution was conducted. The draft Constitution was approved in a poll that took place on 4 August 2010, by 68 percent of those who voted. The objective of the new constitution was to introduce a checks and balances system; it devised a system that augmented accountability. The new constitution was heralded as a significant key with the potential to alter Kenya's socio-economic and political landscape. President Kibaki also promulgated 'Kenya Vision 2030' whose objective is transforming Kenya into "a globally competitive and prosperous country with a high quality of life by 2030." The basic tenets of 'Kenya Vision 2030' and the 'Constitution of Kenya 2010' are steady growth and sustainable development.

\subsection{Socio-Political and Institutional Reforms in Correspondence to 'Green Economy.'}

The new constitution identifies access to a clean and healthy environment as a basic human right and provides for sustainable exploitation, utilization, management and conservation of the environment and natural resources. On the other hand, Kenya Vision 2030 aims at achieving an annual growth of 10 percent per annum. Kenya faces the challenge of sustaining equilibrium between development and conservation of resources. The final document of the Rio+20 summit; The Future We Want, (UNCSD, 2012) highlighted transition to a green economy as a means towards sustainable development. Transitioning could contribute to "eradicating poverty as well as sustained economic growth, enhancing social inclusion, improving human welfare and creating opportunities for employment and decent work for all, while maintaining the healthy functioning of the Earth's ecosystems." $"[2]$ 
The Kenya Green Economy Assessment Report launched by UNEP in 2014 concluded that Kenya is already implementing various green economy approaches and policies and that a transition to a green economy has positive impacts in the medium and long term across all the sectors of the economy. By 2030, a green growth path results in faster growth, a cleaner environment, and high productivity, relative to the 'business as usual' growth scenario. In the Medium Term Plan 2013-2017, the Government committed to develop a green economy strategy. The framework is provided by the Sustainable Development Goals (SDGs) envisioned at the Rio+20 process which facilitates the process of infusing green growth initiatives into the development planning system. Kenya's key policies and programs supportive of a green economy include investments in renewable energy, promotion of resource-efficient and cleaner production, enhanced resilience to economic and climatic shocks, pollution control and waste management, environmental planning and governance, and restoration of forest ecosystems. The conservation of natural resources remains an indispensable element of the Kenyan economy as it is estimated that $42 \%$ of Kenya's GDP and $70 \%$ of overall employment is derived from natural resourcerelated sectors, including agriculture, mining, forestry, fishing, tourism, water supply and energy.

According to the Kenyan Green Economy Strategy and Implementation Plan (GESIP), there are five key crucial challenges to Kenya's transition into becoming a 'Green Economy.' Firstly, the enforcement and compliance of several laws and regulations devised to encourage sustainability across various sectors. Secondly, the requirement of environmental standards for green technologies (such as solar panels), food safety, and animal and crop products. Thirdly, the current economic policy framework in Kenya needs to account for the intrinsic value of its natural capital and support sustainable development. Like most countries, Kenyan prices and policy regime do not fully account for the external costs associated with technologies, products and practices that are environmentally friendly. This also tends to diminish any nascent demand for green alternatives. Therefore, Kenya needs to incorporate natural resources into the system of National Accounts. Fourthly, increased funding will be needed to affect a transition to a green economy due to challenges in up front capital costs, particularly in areas like energy where up-front costs for clean technologies can be high. These funds will need to originate from both the public and private sectors. Efforts to increase awareness of energy efficiency and renewable energy technologies can improve knowledge of best practices, promote the concept of a green economy and provide needed education and outreach.

Finally, a number of cross-sectoral barriers have been identified by Kenyan Green Economy Strategy and Implementation Plan (GESIP) like; youth unemployment, training for adoption of green practices, insufficient awareness about green technologies, obsolete and slow adoption of technology, devolution transitional challenges regarding capacity and policy coordination, capacity to leverage private sector investment, insufficient incentives, low rate of return on green investment and Inadequate access to information on climate and weather data, which can impact resilience.

In order to resolve these challenges, Kenya needs to constitute institutional reforms across public and private sectors. A green mechanism and culture need to be entrenchedinto the system. The Kenyan Green Economy Strategy and Implementation Plan (GESIP) identify some key solutions to the challenges such as; maintaining macroeconomic stability:Macroeconomic stability is one of the key foundations of a sound economic environment for private sector development. Secondly, Green Economy fiscal reform: The fiscal policy framework will continue to align more resources towards infrastructure development and social services, and use policy instruments to promote goals of thegreen economy.

Thirdly, deepening financial inclusion is expected to enhance economic resilience and support the green economy transition. The government will, however, need to explore diversification of financial instruments that support green economy such as green bonds and mortgages. Fourthly,

Employment/Job creation is a key policy concern for the Government, which committed to creating 1 million jobs annually. Green economy will support employment creation through production and trade in green economy technologies, goods and services such as organic and conservation agriculture including production of natural inputs; manufacture and trade in recycled, re-manufactured goods, eco-labeling, production of nontimber forest products (NTFPs) for cosmetics, pharmaceuticals and food industry, ecotourism, integrated waste management, slum upgrading and renewable energy. However, as part of the transition to the green economy it is important that the government addresses key skills bottlenecks. 
Finally, Education remains the single largest sector in terms of public expenditure allocation, in developing a green economy, skills, innovation, and research and development will require increased attention. ${ }^{[2]}$ Research and development for all sectors into the types of green economy practices and technologies that can be implemented is a key part of the implementation. Supporting academic research as well as partnerships with the private sector can assist in developing new technologies and harnessing existing green technologies.Education is a vital aspect of the 'Green Economy' policy as it is the embryonic stage for institutional reforms.

\subsection{Climate Change Action Plan in the Status Quo}

In 2010, the Ministry for Environment and Mineral Resources launched the National Climate Change Response Strategy (NCCRS), complemented by the 2013-2017 Climate Change Action Plan. ${ }^{[3]}$ The Action Plan is the result of a year-long, participatory process involving the public sector, the private sector, academia and civil society, under the leadership of the Ministry of Environment and Mineral Resources guided by a multistakeholder, multidisciplinary taskforce. Climate change is considered a cross-cutting issue that has to be mainstreamed in all the sectors of the economy through the planning process. The Medium-Term Plan (201317), has provided an opportunity to incorporate climate change programs into the national development plans, and build on both the National Climate Change Response Strategy and its Action Plan. ${ }^{[4]}$

Firstly, the NCCRS proposes, calculation of the baseline Greenhouse Gas (GHG) Grid Emission Factor (GEF) for the electricity grid to facilitate Clean Development Mechanism (CDM) projects in the power sector and assist carbon project developers and consultants. Secondly, target capacity building for the private sector and investors to increase awareness of GHG reduction project developments and markets, for instance, developing a detailed handbook on the opportunities, therole of actors and appropriate processes. Thirdly,strengthening relevant institutions and removing barriers to carbon trading such as high initial transaction costs and low level of awareness of CDM potential on the part of theprivate sector, particularly investment and financial organizations. Fourthly, providing tax incentives and favorable import tariffs on technology that reduce emissions. Fifthly, clear energy pricing and CDM project policies including a general institutional framework and good governance.

The key components of the NCCRS proposal also includes ensuring that Kenya establishes itself as a costeffective host country to GHG emission reduction projects, designing a ranking of project types from the easiest and most viable to the most difficult and least viable and finally, creating a database of existing projects, emission reduction volumes, other benefits, project developers, financiers, government support and exploring ways to integrate carbon markets into the main economy.

Over the past five years, the Ministry of Environment and Natural Resources has produced several drafts of a National Environmental Policy (NEP). According to the 13th revised draft (2013), one of the core objectives of the NEP is to establish "a framework for an integrated approach to planning and sustainable management of Kenya's environment and its natural resources. "[4]

The National Climate Change Council was established as an outcome of the Climate Change Bill, which was passed by the parliament in July 2014. In September 2014, the government updated its National Climate Change Policy Framework emphasizing its focus on sustainable development, resilience, and adaptation. The policy proposes to "to enhance adaptive capacity and build resilience to climate variability and change while promoting low carbon development pathways." It also proposes low carbon growth initiatives such as increased geothermal electricity, switching freight from road to rail, reforestation, agro-forestry, promotion of clean technologies, gender equality, participation in voluntary emissions reductionprograms, mainstreaming climate change into planning process and enabling favorable regulatory architecture. ${ }^{[4]}$

\subsection{An Organic Solution?}

Agriculture is the mainstay of Kenya's economy, directly contributing $26 \%$ of GDP and 25\% indirectly. The sector accounts for $65 \%$ of total exports and about $18 \%$ of the formal employment. Over $80 \%$ of the Kenyan population live in the rural areas and derive their livelihoods, directly or indirectly from agriculture. Given its significance, the performance of the sector is therefore reflected in the performance of the entire economy.

In 2004, the Government developed and launched the Strategy for Revitalizing Agriculture (SRA), The SRA set out the Government's vision: To transform Kenya's agriculture into a profitable, commercially oriented and internationally and regionally competitive economic activity that provides high quality, gainful employment to 
Kenyans. ${ }^{[5]}$ The new strategy is required to strategically position the agricultural sector as a key driver for delivering the $10 \%$ annual economic growth rate envisaged under the economic pillar of Vision 2030. Hence, this strategy is perceived as an Agricultural Sector Development Strategy (ASDS) which was announced in 2010. This strategy comprises of three focal points.

First, Revival of agricultural institutions:Institutions that were on the verge of collapse and have since been revived are the Kenya Meat Commission, the Kenya Cooperative Creameries (KCC), the Kenya Seed Company, the Agricultural Finance Corporation, and the Agricultural Development Corporation. Institutions that were considered moribund and dysfunctional, such as research and extension services with their subcentres, training centres and tractor hire are now vibrant and providing services to farmers. Even institutions that were running into losses such as the sugar factories have been revived and are reporting profits and are on the verge of being privatized. ${ }^{[5]}$

Second, Developing Policies and Legislations: In the last 5 years, over 15 policies and 6 pieces of legislation have been developed and are being implemented. Among these are the Seed Policy, the Food Security and Nutrition Policy, the National Dairy Development Policy, the National Agricultural Sector Extension Policy, the Cotton Act 2006 and the Cooperatives Policy. This success is attributed to restructuring ministries by creating directorates and units that are coordinating policy development

Finally, Reducing Food Security and Poverty: The ERS had set a target of reducing foodinsecurity by 23.5 per cent by 2008 and poverty by 26 per cent by 2010. By 2007 foodinsecurity had been reduced by 12 per cent from 48.5 to 36.5 per cent, while povertyhad been reduced by 10 per cent from 56 to 46 per cent. ${ }^{[5]}$

Kenya could resolve numerous issues ranging from food security to unemployment by embracing an organic approach. The growth and development of organic agriculture (farming) in Kenya was initially aninitiative of Non-Governmental Organizations (NGOs) and private organizations like the Kenya Institute of Organic Farming (KIOF), formed back in 1986. ${ }^{[6]}$ However, from the mid1990s, efforts were shifting from isolated individual to more collaborative with the establishmentof organizations such as the Kenya Organic Farmers Association (KOFA), initiatedby farmers participating in KIOF extension and training programs. In 2005, organic agriculture stakeholders in Kenya, including KOPA and KOFA, formed the umbrella network KOAN (Kenya Organic Agricultural Network) to support the continuing successful growth of the organic sector. The National Organic Agriculture Policy development process was launched in 2010. A number of programs and projects are being implemented by various stakeholders to promote organic agriculture. As a report by the United Nations Environment Programme (UNEP) states that the organic sector is relatively small but fast growing and led mainly by civil society organizations (CSOs) and the private sector (companies growing organic produce for export). The main objectives are to diversify production of food at the household level in a sustainable wayand, at the same time, ensure ecological sustainability of the farming systems and increase household incomes through market access. ${ }^{[7]}$

The parliament needs to devise a dynamic and potent mechanism to facilitate the organic practices in Kenya to create a more efficient, robust and necessary market institution and trade network which would act as a cornerstone for the economic mainstay of Kenya - agriculture. An organic approach to agriculture will greatly contribute to the amelioration of major and interrelated issues such as poverty, food security, and displacement of the rural population, ecologically unsustainable farm environments and unemployment.

\subsection{Conclusion}

According to the 2015 Global Climate Change Study, Kenya's natural resource-dependent economy is highly vulnerable to impacts from climate change. More than $70 \%$ of rural livelihoods are dependent on rainfed subsistence agriculture and are affected by declining agricultural production, unpredictable rainfall, reduced soil productivity and soil erosion. The Arid and Semi Arid Lands (ASAL comprises 83\% of Kenya's land mass) are under threat from land degradation and desertification caused by climatic variations, and human impacts such as overgrazing of livestock, deforestation and urbanization.There is loss of biodiversity, change in structure and composition of vegetation, decrease in forest coverage, rapid land cover deterioration, depletion of quality and quantity of water through the destruction of catchments and underground aquifers. Increased frequency of droughts in the ASAL is causing higher livestock morbidity and mortality due to reduced availability of forage, increased disease incidences. Reduction in extreme cold temperature occurrences in the ASALs, increased depletion of glaciers on Mount Kenya, sea level rise, higher frequency and intensity of 
droughts and floods are ascribed to the increasing temperature trends since the 1960s. There is increasing concern about imminent water scarcity. ${ }^{[4]}$ In 2011 the government launched the National Food and Nutrition Security Policy, in which it identified the direct implications of climate change for food and nutrition security. The Policy proposes a set of measures addressing both risk management and adaptation to climate change. The government committed to promote integration of climate change adaptation in agricultural development programmes and policies. The measures include - joint public-private involvement, diversified and sustained production, better storage and creation of strategic reserves, better trade to enable commercial access, on-farm and off-farm employment opportunities, nutrient fortification, cross-sectoral and ministry co-operation, expanding early warning systems and emergency preparedness, cash transfers, public works programmes, institutional and financial mechanisms including advocacy programmes. In addition to assisting local communities to develop rapid adaptation mechanisms, the Policy also sets out to develop more effective mechanisms of drought prevention, preparedness and mitigation; instruments of irrigation. A Drought Management Authority and Drought Contingency Fund to respond to climate change related calamities have been created. ${ }^{[4]}$

However, problems of poverty, unemployment, and poor distributional efficiency - the classical problems of development economics still persist. Kenya can embark upon a phase of steady and sustainable economic growth if there is a legitimate execution of the policies and programmes of 'Vision 2030' which is anchored on three pillars - economic, social and political. Kenya recognized the imminent threat posed by climate change and launched the Climate Change Action Plan (2013-2017). Investments along with a political will to strengthen organic agriculture mechanism with a focus on structural reforms backed up by attention to policy implementation will help Kenya embark upon the next stage of growth and development, by embracing the dynamics of its economic mainstay - agriculture.

\section{Acknowledgements}

Purvi Vyas, Faculty of Food Geography, School of Liberal Studies (PDPU), Email: poorvivyas@ gmail.com

\section{References}

[1] East Africa Living Encyclopedia,' Kenya-History', available:http://www.africa.upenn.edu/NEH/khistory.htm .

[2] Kenyan Green Economy Strategy and Implementation Plan (GESIP), available:http://www.environment.go.ke/wpcontent/uploads/2015/05/Kenya-Green-Economy-Strategy-and-Implementation-Plan-GESIP-.pdf.

[3] National Climate Change Action Plan (2013-2017) - Official.

[4] CLIMATE CHANGE LEGISLATION IN Kenya, from the Global Climate Legislation Study, 2015 pp. 4-9.

[5] AGRICULTURAL SECTOR DEVELOPMENT STRATEGY 2010-2020 - SlideShare, available: http://www.slideshare.net/simbagoma/agricultural-sector-development-strategy-20102020

[6] AFRICA KENYA Organic Food and Farming in Kenya,available:http://orgprints.org/17933/1/kledal-etal-2009-worldorganic-agriculture.pdf.

[7] UNEP-UNCTAD Capacity Building Task Force on Trade, Environment and Development, available: http://www.unep.ch/. 